\title{
An Analysis of Stock Return Transmission in North and Latin America
}

\author{
Chikashi Tsuji ${ }^{1}$ \\ ${ }^{1}$ Faculty of Economics, Chuo University, Tokyo, Japan \\ Correspondence: Chikashi Tsuji, Professor, Faculty of Economics, Chuo University, 742-1 Higashinakano, \\ Hachioji-shi, Tokyo 192-0393, Japan. E-mail: mail_sec_low@minos.ocn.ne.jp
}

Received: September 29, 2019

Accepted: October 13, $2019 \quad$ Online Published: October 16, 2019

doi:10.5430/ijba.v10n6p14

URL: https://doi.org/10.5430/ijba.v10n6p14

\begin{abstract}
This study empirically examines the return transmission effects between the four North and Latin American stock markets in the US, Canada, Brazil, and Mexico. More specifically, applying a standard vector autoregression (VAR) model, we obtain the following interesting findings. First, (1) the return transmission effects between the four North and Latin American stock markets became much tighter in our second subsample period. Second, (2) in particular, US and Mexican stock markets are strong return transmitters in the recent period. Furthermore, (3) both in our first and second subsample periods, Brazilian stock returns do not transmit to the other three stock returns, although the other three North and Latin American stock markets affect the Brazilian stock market.
\end{abstract}

Keywords: Latin American stock market, North American stock market, return transmission, VAR model

\section{Introduction}

The return nexuses between international stock markets have recently become the subject of research, and there indeed exist some extant studies on return transmission (e.g., Arouri et al., 2011a, 2011b, 2012; Kim et al., 2015; Syriopoulos et al., 2015; Tsuji, 2018a, 2018b, 2019), with the studies of volatility spillovers in financial and commodity markets (e.g., Savva et al., 2009; Diebold and Yilmaz, 2009, 2012; Maghyereh and Awartani, 2012; Sadorsky, 2012; Balli et al., 2015; Gamba-Santamaria et al., 2017; Guo, 2017; Leung et al., 2017). However, regardless of its significance of examinations, existing studies focusing on the return transmission in North and Latin American stock markets are limited.

Based on this, in this study, we investigate how return transmission arises in North and Latin American stock markets. More concretely, applying a standard vector autoregression (VAR) model, this study explores the return transmission between the four North and Latin American stock markets in the US, Canada, Brazil, and Mexico. Our research question in this study is, between the four North and Latin American markets, how return transmission arises and how the return transmission changes over time. Therefore, we use two subsample periods in our analyses and compare the results from the two periods. As a result, this study obtains the following interesting findings.

That is, for our first subsample period, first, (1) US stock returns transmit to the next day's Canadian and Mexican stock returns. Second, (2) Mexican stock returns transmit to the next day's Brazilian stock returns. Third, (3) Brazilian stock returns rapidly transmit to their own future stock returns. Moreover, (4) Mexican stock returns also transmit to their own future stock returns. Next, for our second subsample period, first, (1) US stock returns transmit to the next day's Canadian, Brazilian, and Mexican stock returns, and the second lag of US stock returns also transmit to Canadian stock returns. Second, (2) the second, third, and fourth lags of Canadian stock returns also transmit to US stock returns. Third, (3) Mexican stock returns transmit to the next day's US, Canadian, and Brazilian stock returns. Fourth, (4) Mexican stock returns transmit to their own future stock returns again in the second subsample period.

With regard to the rest of this paper, Section 2 conducts a short literature review, Section 3 explains the data for our empirical examinations, and Section 4 describes our model and methods. Section 5 describes our empirical results, and Section 6 concludes the paper.

\section{Recent Literature Review}

This section conducts a short literature review of recent existing studies. As we noted, extant studies of return transmission in North and Latin American stock markets are limited, thus past studies we review in this section are 
not always regarding North and Latin American stock markets. First, Arouri et al. (2011a) empirically examined volatility spillovers between US and European sector stocks and crude oil. They showed that some volatility spillovers were bidirectional in the US, whereas volatility spillovers were generally unidirectional from crude oil to sector stocks in Europe. Further, using BEKK-GARCH techniques, Ewing and Malik (2016) investigated crude oil and US equity market volatilities by focusing on the effect of structural breaks. They found that when incorporating structural breaks into their models, the volatility spillover effects between the two markets became clearer.

Later, by extending the approach of Diebold and Yilmaz (2009, 2012), Gamba-Santamaria et al. (2017) composed volatility spillover indices for the stock markets of the US and four Latin American countries. They found that in Latin America, the stock markets of Chile, Colombia, and Mexico were net volatility receivers, while the Brazilian stock market was generally a net volatility transmitter. Moreover, Tsuji (2018a) examined return transmission between WTI crude oil and international oil equities, comprising North American and Latin American regions. This study found evidence of bidirectional return transmission between crude oil and Latin American oil equities, and unidirectional return transmission from North American oil equities to crude oil. Lastly, Tsuji (2019) examined stock return transmission between the US and other international banking sectors, and found evidence of mostly unidirectional return transmission from the US to other international banking sectors.

As above, several past studies examined return transmission in various contexts; however, again, regardless of its interest of related industries and researchers, the studies of return transmission in North and Latin American stock markets are limited. In this study, therefore, by using US, Canadian, Brazilian, and Mexican stock return data and a VAR model, we empirically examine the return transmission effects between the four markets.

\section{Data}

In this section, we explain our data and time-series variables we construct for our empirical analyses. Using raw stock price data supplied by Thomson Reuters, we compute and construct four daily log difference percentage stock returns. More concretely, USLR denotes the log return of the Standard and Poor's 500 Composite Index; CANLR denotes the log return of the Standard and Poor's Toronto Stock Exchange Composite Index; BRALR is that of the Bovespa Index from Sao Paulo Stock Exchange; and MEXLR is that of the MXIPC35 Index from Mexican Stock Exchange. The full sample period of these returns in our study is from January 2, 1992 to September 20, 2019. The first subsample period is from January 2, 1992 to December 30, 2005, and the second subsample period is from January 2, 2006 to September 20, 2019.

Figure 1 plots the dynamic price evolution as regards the above four stock price indices of North and Latin America over our full sample period, January 2, 1992 to September 20, 2019. From this figure, we understand that the trends of the four stock price indices are roughly similar. Table 1 exhibits the summary statistics for the four stock returns. As Panel A of Table 1 presents, in the first subsample period, the mean value of BRALR is higher than those of the other three stock returns. Further, the standard deviation value for BRALR is also higher than those of the other three stock returns. Furthermore, interestingly, the skewness for BRALR shows much higher positive value, while the skewness values of the other three stock returns show negative values. In addition, for all the four returns, their kurtosis values are higher than three, which is the kurtosis value of normal distributions.

Next, as Panel B of Table 1 displays, in the second subsample period, there is little particular characteristic for all of the four stock returns. However, as with the first subsample period, it is noted that for the four stock returns, their kurtosis values are again all higher than that of normal distributions.

\section{Methods}

This section explains the methods for our investigations. To explore the return transmission effects between the four North and Latin American stock markets, this study uses the following five-lag VAR model:

$$
\begin{aligned}
r_{i, t}=c_{i}+\sum_{j=1}^{4} \alpha_{i, j} r_{j, t-1}+ & \sum_{j=1}^{4} \beta_{i, j} r_{j, t-2}+\sum_{j=1}^{4} \gamma_{i, j} r_{j, t-3} \\
& +\sum_{j=1}^{4} \lambda_{i, j} r_{j, t-4}+\sum_{j=1}^{4} \delta_{i, j} r_{j, t-5}+\varepsilon_{i, t}, \text { for } i=1, \ldots, 4 .
\end{aligned}
$$

In this model (1), $r_{i, t}$ means the stock return $i ; r_{j, t-k}$ denotes the $k$ th lag of stock return $j ; c_{i}, \alpha_{i, j}, \beta_{i, j}, \gamma_{i, j}, \lambda_{i, j}$, and $\delta_{i, j}$ denote the coefficients; and $\varepsilon_{i, t}$ means the error term. While this study is interested in the fast return transmission between the four North and Latin American stock markets, one week comprises five business days; hence this study employs the above five-lag VAR model. We note that throughout this paper, in the use of the model (1), we specify US, Canadian, Brazilian, and Mexican stock returns as $i=1$ to 4 , respectively. 
Panel A. US

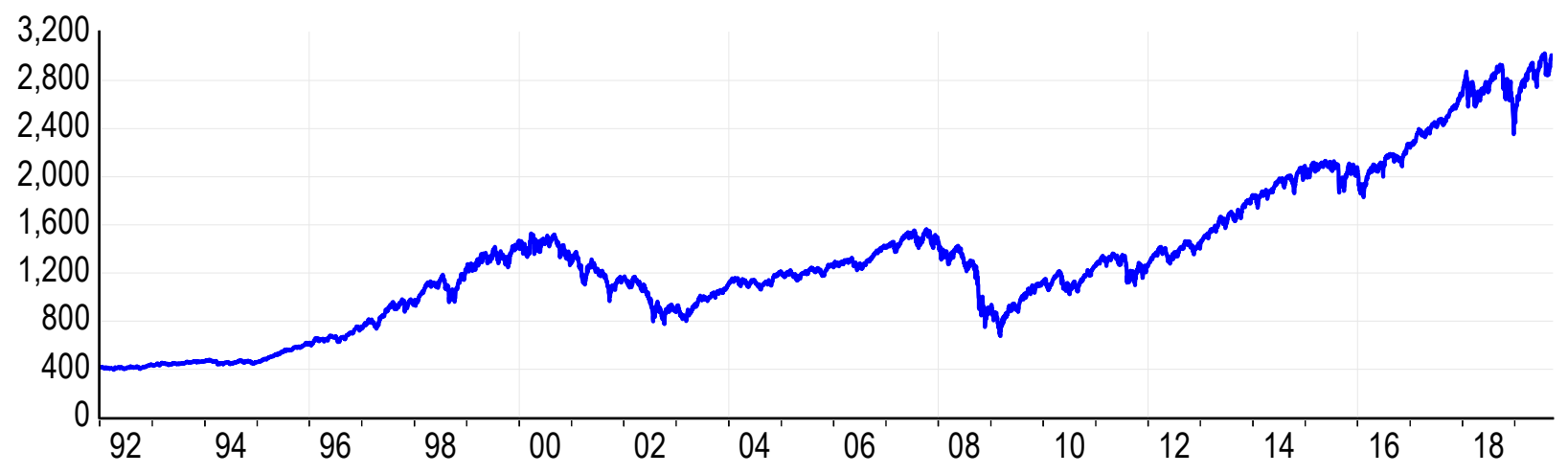

Panel B. Canada

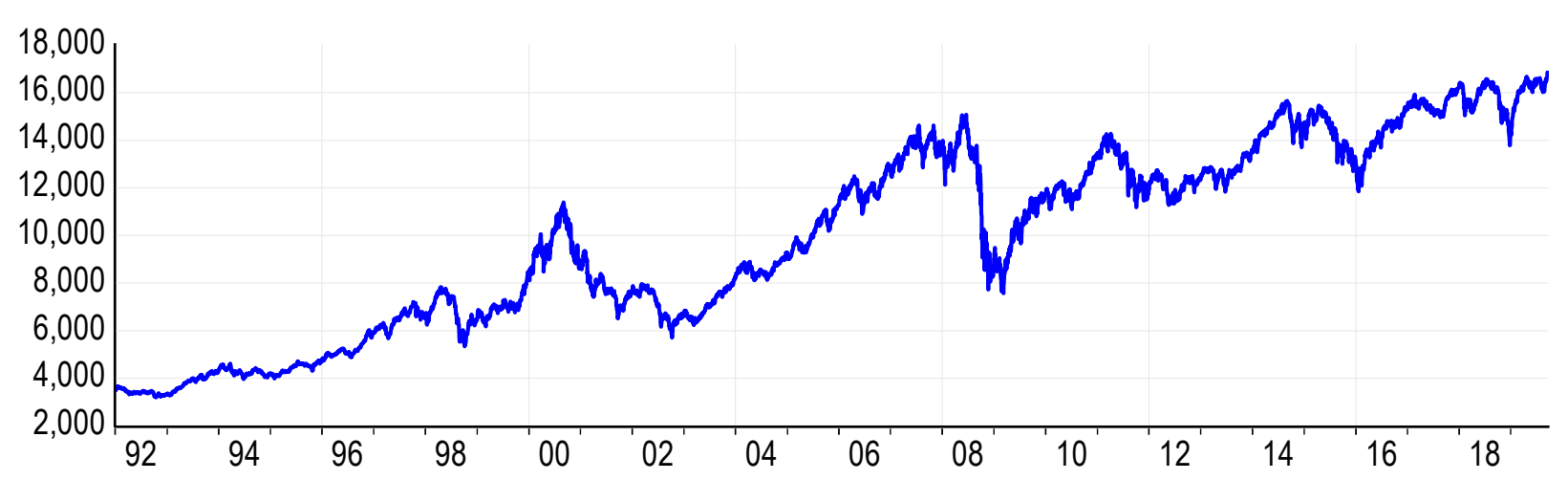

Panel C. Brazil

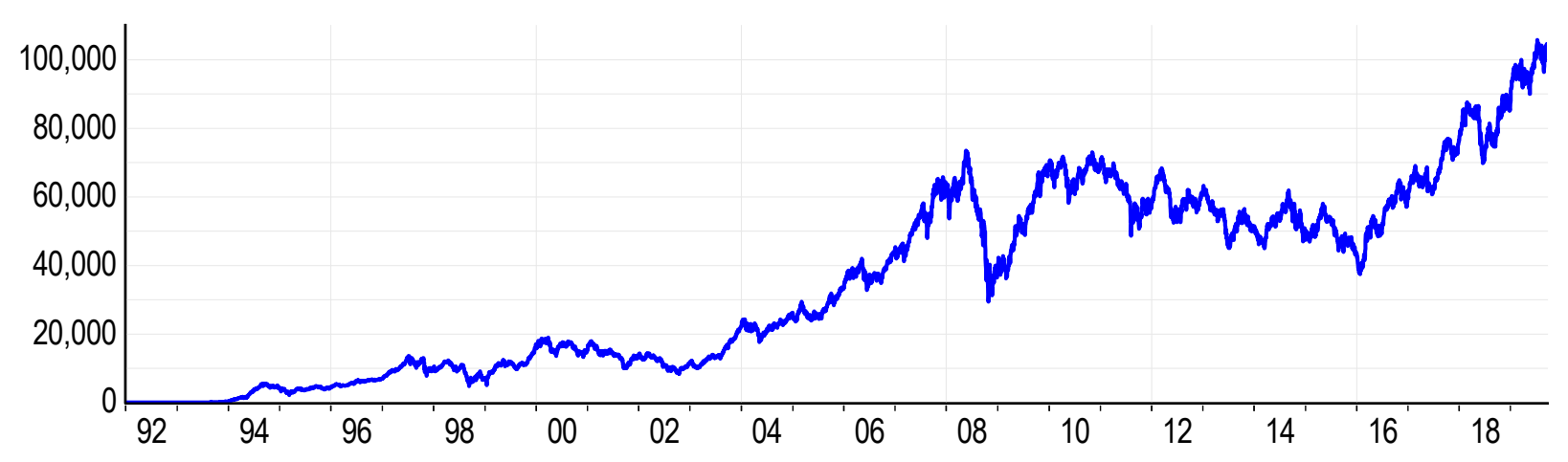

Panel D. Mexico

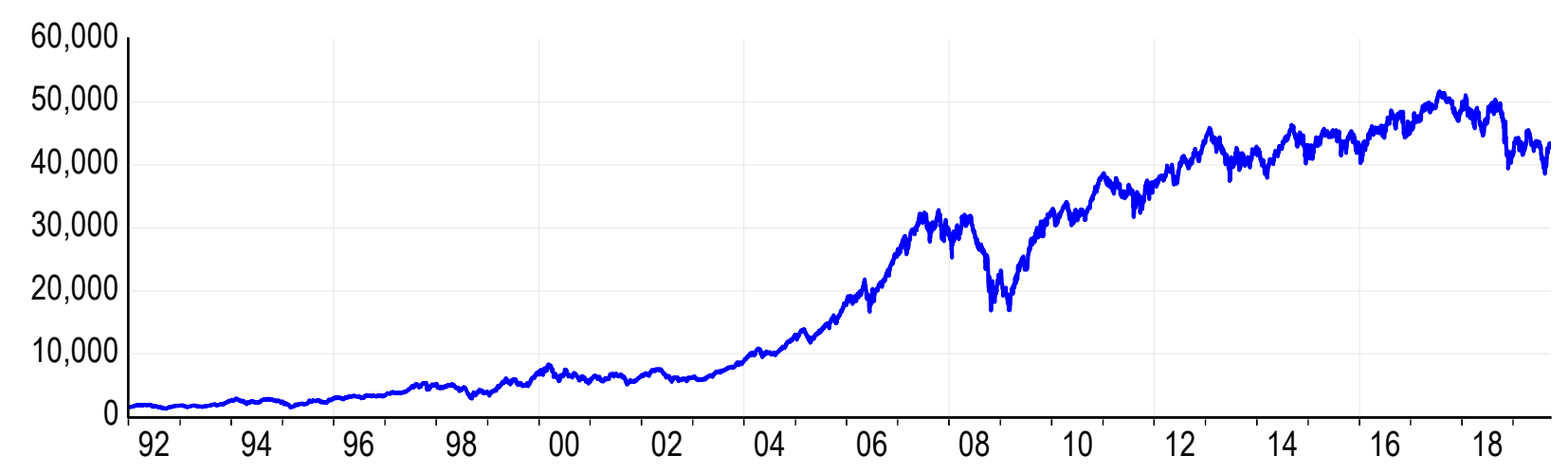

Figure 1. Stock market evolution in the US, Canada, Brazil, and Mexico 
Table 1. Summary statistics for North and Latin American stock returns

\begin{tabular}{lllll}
\hline Panel A. First subsample period & & & & \\
\hline Statistic & USLR & CANLR & BRALR & MEXLR \\
\hline Mean & 0.030 & 0.032 & 0.299 & 0.069 \\
Median & 0.012 & 0.040 & 0.126 & 0.003 \\
Maximum & 5.573 & 4.684 & 28.832 & 12.154 \\
Minimum & -7.113 & -8.465 & -17.208 & -14.314 \\
Standard deviation & 1.004 & 0.883 & 2.824 & 1.611 \\
Skewness & -0.107 & -0.733 & 0.449 & -0.002 \\
Kurtosis & 7.289 & 10.553 & 10.037 & 8.980 \\
\hline Panel B. Second subsample period & & & & \\
\hline Statistic & USLR & CANLR & BRALR & MEXLR \\
\hline Mean & 0.024 & 0.011 & 0.032 & 0.025 \\
Median & 0.035 & 0.043 & 0.000 & 0.019 \\
Maximum & 10.957 & 9.370 & 13.678 & 10.441 \\
Minimum & -9.470 & -9.788 & -12.096 & -7.266 \\
Standard deviation & 1.176 & 1.059 & 1.656 & 1.188 \\
Skewness & -0.377 & -0.718 & -0.047 & 0.070 \\
Kurtosis & 14.810 & 15.513 & 9.264 & 10.533 \\
\hline
\end{tabular}

Notes: This table shows the summary statistics for the daily log North and Latin American stock returns. Our first subsample period is from January 2, 1992 to December 30, 2005, with 3652 daily observations (Panel A), and our second subsample period is from January 2, 2006 to September 20, 2019, with 3580 daily observations (Panel B). USLR denotes the US stock return, CANLR denotes the Canadian stock return, BRALR is the Brazilian stock return, and MEXLR is the Mexican stock return.

\section{Results}

In this section, we document our empirical results. First, in Table 2, the estimation results of the VAR model for our first subsample period are presented. It is noted that the bold figures in this table mean the statistically significantly positive return transmission. As Table 2 shows, we mainly reveal the cross-country return transmission in the four North and Latin American stock markets as follows. First, (1) US stock returns transmit to the next day's Canadian and Mexican stock returns. Second, (2) Mexican stock returns transmit to the next day's Brazilian stock returns.

Moreover, we also clarify the autoregressive return relations for the four North and Latin American stock markets as follows. First, (1) Brazilian stock returns rapidly transmit to their own future stock returns. Second, (2) Mexican stock returns also transmit to their own future stock returns.

Next, in Table 3, the estimation results of the VAR model for our second subsample period are exhibited. We again note that the bold figures in Table 3 mean the statistically significant return transmission with positive signs. As Table 3 shows, as for the rapid cross-country return transmission in the four North and Latin American stock markets, we firstly find that (1) US stock returns transmit to the next day's Canadian, Brazilian, and Mexican stock returns. We note that the second lag of US stock returns also transmit to Canadian stock returns. Second, (2) the second, third, and fourth lags of Canadian stock returns also transmit to US stock returns. Third, (3) Mexican stock returns transmit to the next day's US, Canadian, and Brazilian stock returns.

Further, as regards the rapid autoregressive return relations, our results indicate that Mexican stock returns transmit to their own next day's stock returns also in the second subsample period.

Overall, our results suggest that both in the first and second subsample periods, Brazilian stock returns do not transmit to the other three stock returns. Moreover, our results also present that return transmission effects between the four North and Latin American stock markets became much tighter in our second subsample period. 
Table 2. Estimation results of the five-lag VAR model for the first subsample period

\begin{tabular}{|c|c|c|c|c|}
\hline & USLR & CANLR & BRALR & MEXLR \\
\hline $\operatorname{USLR}(-1)$ & -0.020 & $0.080 * * *$ & -0.049 & 0.064* \\
\hline$p$-value & 0.407 & 0.000 & 0.458 & 0.093 \\
\hline $\operatorname{USLR}(-2)$ & -0.026 & 0.027 & $-0.128 *$ & 0.007 \\
\hline$p$-value & 0.282 & 0.197 & 0.055 & 0.863 \\
\hline $\operatorname{USLR}(-3)$ & -0.028 & 0.020 & -0.031 & -0.009 \\
\hline$p$-value & 0.246 & 0.349 & 0.639 & 0.821 \\
\hline $\operatorname{USLR}(-4)$ & $-0.044^{*}$ & -0.006 & 0.035 & -0.042 \\
\hline$p$-value & 0.063 & 0.786 & 0.603 & 0.268 \\
\hline $\operatorname{USLR}(-5)$ & -0.018 & $0.040 *$ & -0.040 & -0.013 \\
\hline$p$-value & 0.435 & 0.052 & 0.547 & 0.733 \\
\hline CANLR(-1) & -0.013 & 0.006 & -0.055 & -0.053 \\
\hline$p$-value & 0.620 & 0.793 & 0.454 & 0.206 \\
\hline CANLR(-2) & 0.010 & $-0.042^{*}$ & 0.091 & -0.053 \\
\hline$p$-value & 0.697 & 0.065 & 0.214 & 0.208 \\
\hline CANLR(-3) & 0.004 & -0.002 & 0.099 & 0.067 \\
\hline$p$-value & 0.878 & 0.923 & 0.176 & 0.110 \\
\hline CANLR(-4) & 0.043* & -0.019 & 0.023 & 0.009 \\
\hline$p$-value & 0.099 & 0.411 & 0.751 & 0.830 \\
\hline CANLR(-5) & 0.002 & -0.036 & 0.105 & 0.023 \\
\hline$p$-value & 0.928 & 0.112 & 0.146 & 0.577 \\
\hline $\operatorname{BRALR}(-1)$ & 0.004 & 0.007 & $0.046 * *$ & -0.005 \\
\hline$p$-value & 0.522 & 0.199 & 0.011 & 0.623 \\
\hline $\operatorname{BRALR}(-2)$ & -0.004 & -0.007 & $0.033^{*}$ & 0.007 \\
\hline$p$-value & 0.577 & 0.239 & 0.067 & 0.528 \\
\hline $\operatorname{BRALR}(-3)$ & -0.007 & -0.001 & -0.001 & $-2.3 \mathrm{E}-04$ \\
\hline$p$-value & 0.283 & 0.804 & 0.948 & 0.982 \\
\hline $\operatorname{BRALR}(-4)$ & -0.002 & 0.003 & -0.001 & -0.012 \\
\hline$p$-value & 0.819 & 0.649 & 0.944 & 0.243 \\
\hline $\operatorname{BRALR}(-5)$ & -0.006 & 0.004 & 0.007 & 0.002 \\
\hline$p$-value & 0.395 & 0.499 & 0.687 & 0.842 \\
\hline $\operatorname{MEXLR}(-1)$ & 0.007 & 0.012 & $0.136 * * *$ & $0.114 * * *$ \\
\hline$p$-value & 0.581 & 0.283 & 0.000 & 0.000 \\
\hline $\operatorname{MEXLR}(-2)$ & 0.001 & 0.014 & $-0.061 *$ & -0.028 \\
\hline$p$-value & 0.960 & 0.201 & 0.081 & 0.159 \\
\hline $\operatorname{MEXLR}(-3)$ & -0.005 & 0.011 & -0.003 & -0.023 \\
\hline$p$-value & 0.670 & 0.323 & 0.932 & 0.256 \\
\hline $\operatorname{MEXLR}(-4)$ & 0.006 & -0.011 & -0.023 & $0.047 * *$ \\
\hline$p$-value & 0.623 & 0.315 & 0.516 & 0.020 \\
\hline $\operatorname{MEXLR}(-5)$ & -0.012 & -0.011 & -0.005 & -0.006 \\
\hline$p$-value & 0.340 & 0.319 & 0.890 & 0.766 \\
\hline Constant & $0.037 * *$ & $0.027 *$ & $0.265 * * *$ & $0.063 * *$ \\
\hline$p$-value & 0.030 & 0.066 & 0.000 & 0.020 \\
\hline
\end{tabular}

Notes: USLR, CANLR, BRALR, and MEXLR are US, Canadian, Brazilian, and Mexican stock returns. USLR $(-k)$, $\operatorname{CANLR}(-k), \operatorname{BRALR}(-k)$, and $\operatorname{MEXLR}(-k)$ are the kth lag of the four stock returns. ***,**, and * indicate $1 \%, 5 \%$, and $10 \%$ significance levels. Bold figures indicate statistically significantly positive parameter estimates. 
Table 3. Estimation results of the five-lag VAR model for the second subsample period

\begin{tabular}{|c|c|c|c|c|}
\hline & USLR & CANLR & BRALR & MEXLR \\
\hline $\operatorname{USLR}(-1)$ & -0.042 & $0.144 * * *$ & $0.103 * *$ & $0.073 * *$ \\
\hline$p$-value & 0.145 & 0.000 & 0.011 & 0.012 \\
\hline $\operatorname{USLR}(-2)$ & $-0.080 * * *$ & $0.063 * *$ & -0.038 & -0.033 \\
\hline$p$-value & 0.006 & 0.016 & 0.354 & 0.259 \\
\hline $\operatorname{USLR}(-3)$ & 0.005 & 0.041 & 0.045 & -0.021 \\
\hline$p$-value & 0.864 & 0.122 & 0.282 & 0.478 \\
\hline $\operatorname{USLR}(-4)$ & $-0.050^{*}$ & -0.026 & $-0.106^{* * *}$ & $-0.050 *$ \\
\hline$p$-value & 0.086 & 0.325 & 0.010 & 0.091 \\
\hline $\operatorname{USLR}(-5)$ & 0.008 & 0.027 & 0.062 & 0.027 \\
\hline$p$-value & 0.764 & 0.292 & 0.117 & 0.339 \\
\hline CANLR $(-1)$ & $-0.152 * * *$ & $-0.203^{* * *}$ & -0.048 & $-0.085^{* * *}$ \\
\hline$p$-value & 0.000 & 0.000 & 0.249 & 0.004 \\
\hline CANLR(-2) & $0.061 * *$ & $-0.094 * * *$ & 0.062 & 0.023 \\
\hline$p$-value & 0.041 & 0.000 & 0.142 & 0.444 \\
\hline CANLR(-3) & $0.071 * *$ & 0.015 & 0.027 & $0.071 * *$ \\
\hline$p$-value & 0.018 & 0.585 & 0.532 & 0.020 \\
\hline CANLR(-4) & $0.065^{* *}$ & $0.079 * * *$ & $0.168 * * *$ & $0.055^{*}$ \\
\hline$p$-value & 0.029 & 0.003 & 0.000 & 0.066 \\
\hline CANLR(-5) & $-0.079 * * *$ & $-0.119 * * *$ & $-0.133 * * *$ & $-0.069 * *$ \\
\hline$p$-value & 0.007 & 0.000 & 0.001 & 0.019 \\
\hline $\operatorname{BRALR}(-1)$ & -0.007 & 0.021 & $-0.096^{* * *}$ & -0.020 \\
\hline$p$-value & 0.697 & 0.172 & 0.000 & 0.257 \\
\hline $\operatorname{BRALR}(-2)$ & -0.004 & $1.7 \mathrm{E}-04$ & -0.017 & 0.021 \\
\hline$p$-value & 0.819 & 0.991 & 0.494 & 0.235 \\
\hline $\operatorname{BRALR}(-3)$ & $-0.061 * * *$ & $-0.029^{*}$ & $-0.064 * * *$ & $-0.053 * * *$ \\
\hline$p$-value & 0.000 & 0.056 & 0.008 & 0.002 \\
\hline $\operatorname{BRALR}(-4)$ & -0.013 & -0.012 & -0.015 & -0.012 \\
\hline$p$-value & 0.462 & 0.442 & 0.525 & 0.478 \\
\hline $\operatorname{BRALR}(-5)$ & 0.011 & 0.007 & 0.037 & 0.028 \\
\hline$p$-value & 0.521 & 0.659 & 0.126 & 0.103 \\
\hline $\operatorname{MEXLR}(-1)$ & $0.077 * * *$ & $0.051^{* * *}$ & $0.092 * * *$ & $0.102 * * *$ \\
\hline$p$-value & 0.002 & 0.022 & 0.008 & 0.000 \\
\hline $\operatorname{MEXLR}(-2)$ & 0.001 & 0.017 & -0.009 & -0.033 \\
\hline$p$-value & 0.977 & 0.437 & 0.796 & 0.189 \\
\hline $\operatorname{MEXLR}(-3)$ & 0.019 & -0.007 & -0.020 & -0.026 \\
\hline$p$-value & 0.435 & 0.766 & 0.565 & 0.303 \\
\hline $\operatorname{MEXLR}(-4)$ & 0.002 & 0.001 & -0.031 & 0.005 \\
\hline$p$-value & 0.946 & 0.948 & 0.378 & 0.852 \\
\hline $\operatorname{MEXLR}(-5)$ & -0.016 & -0.002 & -0.049 & $-0.054 * *$ \\
\hline$p$-value & 0.513 & 0.940 & 0.155 & 0.029 \\
\hline Constant & 0.028 & 0.007 & 0.033 & 0.025 \\
\hline$p$-value & 0.148 & 0.691 & 0.229 & 0.203 \\
\hline
\end{tabular}

Notes: USLR, CANLR, BRALR, and MEXLR are US, Canadian, Brazilian, and Mexican stock returns. USLR $(-k)$, $\operatorname{CANLR}(-k), \operatorname{BRALR}(-k)$, and $\operatorname{MEXLR}(-k)$ are the kth lag of the four stock returns. ***, **, and $*$ indicate $1 \%, 5 \%$, and $10 \%$ significance levels. Bold figures indicate statistically significantly positive parameter estimates. 


\section{Conclusions}

This study analyzed the return transmission effects between the four North and Latin American stock markets in the US, Canada, Brazil, and Mexico. The main findings from our investigations are as follows. That is, for our first subsample period, first, (1) US stock returns transmitted to the next day's Canadian and Mexican stock returns. Second, (2) Mexican stock returns transmitted to the next day's Brazilian stock returns. Third, (3) Brazilian stock returns rapidly transmitted to their own future stock returns. Furthermore, (4) Mexican stock returns also transmitted to their own future stock returns.

Next, for our second subsample period, first, (1) US stock returns transmitted to the next day's Canadian, Brazilian, and Mexican stock returns. In addition, we also find that the second lag of US stock returns also transmitted to Canadian stock returns. Second, (2) the second, third, and fourth lags of Canadian stock returns also transmitted to US stock returns. Third, (3) Mexican stock returns transmitted to the next day's US, Canadian, and Brazilian stock returns. Fourth, (4) Mexican stock returns transmitted to their own next day's stock returns also in the second subsample period.

Overall, our results suggested that both in our first and second subsample periods, Brazilian stock returns did not transmit to the other three stock returns. Moreover, our results also presented that return transmission effects between the four North and Latin American stock markets became much tighter in our second subsample period.

We consider that the empirical results demonstrated in this study are highly useful for deepening our understanding and advancing our knowledge of North and Latin American stock market linkages, and therefore further investigations using more sophisticated techniques is one of our future works.

\section{Acknowledgements}

The author firstly acknowledges this journal for its repeated kind article invitation. The author also highly appreciates Jenny Zhang for her kind editorial support. Further, the author greatly thanks an editor of this journal and an anonymous referee for their supportive comments on this paper. Furthermore, the author also appreciates the financial support of a Grant-in-Aid for Scientific Research from the Japan Society for the Promotion of Science and the Chuo University Personal Research Grant to my research. Finally, I greatly thank all the editors of this journal for their kind attention to this paper.

\section{References}

Arouri, M. E. H., Jouini, J., \& Nguyen, D. K. (2011a). Volatility spillovers between oil prices and stock sector returns: Implications for portfolio management. Journal of International Money and Finance, 30, 1387-1405. https://doi.org/10.1016/j.jimonfin.2011.07.008

Arouri, M. E. H., Jouini, J., \& Nguyen, D. K. (2012). On the impacts of oil price fluctuations on European equity markets: Volatility spillover and hedging effectiveness. Energy Economics, 34, 611-617. https://doi.org/10.1016/j.eneco.2011.08.009

Arouri, M. E. H., Lahiani, A., \& Nguyen, D. K. (2011b). Return and volatility transmission between world oil prices and stock markets of the GCC countries. Economic Modelling, 28, 1815-1825. https://doi.org/10.1016/j.econmod.2011.03.012

Balli, F., Hajhoj, H. R., Basher, S. A., \& Ghassan, H. B. (2015). An analysis of returns and volatility spillovers and their determinants in emerging Asian and Middle Eastern countries. International Review of Economics and Finance, 39, 311-325. https://doi.org/10.1016/j.iref.2015.04.013

Diebold, F. X., \& Yilmaz, K. (2009). Measuring financial asset return and volatility spillovers, with application to global equity markets. Economic Journal, 119, 158-171. https://doi.org/10.3386/w13811

Diebold, F. X., \& Yilmaz, K. (2012). Better to give than to receive: Predictive directional measurement of volatility spillovers. International Journal of Forecasting, 28, 57-66. https://doi.org/10.1016/j.ijforecast.2011.02.006

Ewing, B. T., \& Malik, F. (2016). Volatility spillovers between oil prices and the stock market under structural breaks. Global Finance Journal, 29, 12-23. https://doi.org/10.1016/j.gfj.2015.04.008

Gamba-Santamaria, S., Gomez-Gonzalez, J. E., Hurtado-Guarin, J. L., \& Melo-Velandia, L. F. (2017). Stock market volatility spillovers: Evidence for Latin America. Finance Research Letters, 20, $207-216$. https://doi.org/10.1016/j.frl.2016.10.001

Guo, Z. P. (2017). How information is transmitted across the nations? An empirical investigation of the US and Chinese commodity markets. Global Journal of Management and Business Research, 17, 1-11. 
https://doi.org/10.2139/ssrn.3013797

Kim, B. H., Kim, H., \& Lee, B. S. (2015). Spillover effects of the U.S. financial crisis on financial markets in emerging Asian countries. International Review of Economics and Finance, 39, 192-210. https://doi.org/10.1016/j.iref.2015.04.005

Leung, H., Schiereck, D., \& Schroeder, F. (2017). Volatility spillovers and determinants of contagion: Exchange rate and equity markets during crises. Economic Modelling, 61, 169-180. https://doi.org/10.1016/j.econmod.2016.12.011

Maghyereh, A., \& Awartani, B. (2012). Return and volatility spillovers between Dubai financial market and Abu Dhabi Stock Exchange in the UAE. Applied Financial Economics, 22, 837-848. https://doi.org/10.1080/09603107.2011.628292

Sadorsky, P. (2012). Correlations and volatility spillovers between oil prices and the stock prices of clean energy and technology companies. Energy Economics, 34, 248-255. https://doi.org/10.1016/j.eneco.2011.03.006

Savva, C. S., Osborn, D. R., \& Gill, L. (2009). Spillovers and correlations between US and major European stock markets: The role of the euro. Applied Financial Economics, 19, 1595-1604. https://doi.org/10.1080/09603100802599563

Syriopoulos, T., Makram, B., \& Boubaker, A. (2015). Stock market volatility spillovers and portfolio hedging: BRICS and the financial crisis. International Review of Financial Analysis, 39, 7-18. https://doi.org/10.1016/j.irfa.2015.01.015

Tsuji, C. (2018a). Return transmission and asymmetric volatility spillovers between oil futures and oil equities: New DCC-MEGARCH analyses. Economic Modelling, 74, 167-185. https://doi.org/10.1016/j.econmod.2018.05.007

Tsuji, C. (2018b). New DCC analyses of return transmission, volatility spillovers, and optimal hedging among oil futures and oil equities in oil-producing countries. Applied Energy, 229, 1202-1217. https://doi.org/10.1016/j.apenergy.2018.08.008

Tsuji, C. (2019). Correlation and spillover effects between the US and international banking sectors: New evidence and implications for risk management. International Review of Financial Analysis, forthcoming. 